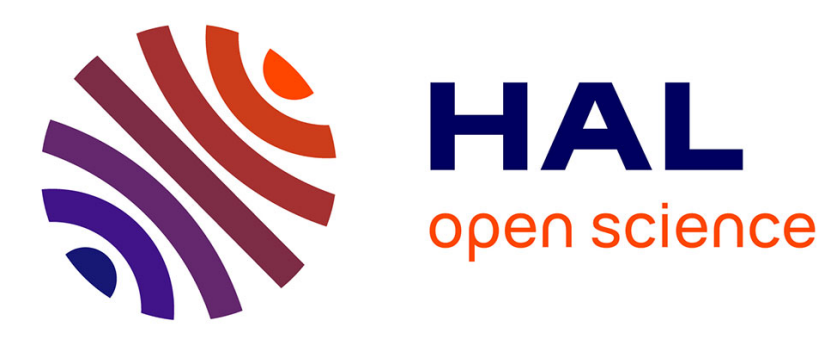

\title{
HCI, Music and Art: An Interview with Wendy Mackay
}

Marcelo M. Wanderley, Wendy Mackay

\section{To cite this version:}

Marcelo M. Wanderley, Wendy Mackay. HCI, Music and Art: An Interview with Wendy Mackay. Simon Holland; Tom Mudd; Katie Wilkie-McKenna; Andrew McPherson; Marcelo M. Wanderley. New Directions in Music and Human-Computer Interaction, Springer, pp.1-22, 2019, Springer Series on Cultural Computing, 978-3-319-92068-9. 10.1007/978-3-319-92069-6_7 . hal-02426818

\section{HAL Id: hal-02426818 https://hal.inria.fr/hal-02426818}

Submitted on 7 Jan 2020

HAL is a multi-disciplinary open access archive for the deposit and dissemination of scientific research documents, whether they are published or not. The documents may come from teaching and research institutions in France or abroad, or from public or private research centers.
L'archive ouverte pluridisciplinaire HAL, est destinée au dépôt et à la diffusion de documents scientifiques de niveau recherche, publiés ou non, émanant des établissements d'enseignement et de recherche français ou étrangers, des laboratoires publics ou privés. 


\title{
Chapter 7
}

\section{HCI, Music and Art: An Interview with Wendy Mackay}

\section{Marcelo M. Wanderley and Wendy E. Mackay}

\begin{abstract}
Wendy E. Mackay is a Research Director at Inria Saclay-île-de-France where she founded and directs the ExSitu research group in Human-Computer Interaction. She is a former chair of CHI. Her research interests include multidisciplinary, participatory design methods, tangible computing, interactive paper, and situated interaction. In this interview, Mackay discusses working with artists, designers and scientists to build tools for highly creative people to support exploration, execution and sparking ideas without the tools getting in their way. Mackay discusses the principles of discoverability, appropriability and how they relate to co-adaptation for interaction designers. She emphasises the importance of evaluating what people actually do, as opposed to what they are supposed to do with technology.
\end{abstract}

\footnotetext{
This interview was conducted by Marcelo Wanderley on February $1^{\text {rst }} 2018$ at Inria Saclay in France. The interview was transcribed by Catherine Massie-Laberge and Johnny Sullivan, and was edited for length and clarity by Marcelo Wanderley. Wendy Mackay's research was supported by ERC grant $\mathrm{n}^{\circ} 321135$ CREATIV: Creating Co-Adaptive Human-Computer Partnerships.
}

This is the author version of the work. It is posted here for your personal use. Not for redistribution. The definitive Version of Record is published in:

S. Holland et al. (eds.) New Directions in Music and Human-Computer Interaction, Springer Series on Cultural Computing. Springer Nature Switzerland AG 2019

DOI: https://doi.org/10.1007/978-3-319-92069-6_7 
Marcelo. How did you first become involved in HCI research and what motivated you to undertake research in this filed?

Wendy. I started doing HCI research before I knew there was such a thing. I was working on a thesis in experimental psychology — teaching monkeys how to talk, but that's another story. My thesis advisor suddenly disappeared, and I found myself without an advisor and without much money. So I took what I thought would be a temporary job at what was then Digital Equipment Corporation (DEC). I arrived at a very interesting time. A women engineer, named Lynn Olsen, had just invented hardware that displayed video on a computer monitor. At the time, we had black and white monitors with twenty-four lines by eighty characters, without vector graphics. But we could display video. My first computer course in college involved writing programs on punch cards, which I found very boring. I was convinced I would never touch a computer again. But when I got to DEC, I realized that we could use video technology to teach people like me how to use a computer. So I wrote an interactive teaching program, called VMSCAI, that taught people how to use the DEC's operating system, VMS (similar to Linux today).

The next step was to write a programming environment for creating more interactive courses. I ended up running a software production group that produced a variety of interactive teaching courses, some of which were bundled with DEC's computers. Customers who bought VAX computers automatically got our course that taught them how to use the computer, the text editor, etc. We took advantage of videodisc technology, which gave us very high-quality video, to push the limits of interactive video courseware, and created over 35 different courses in a period of three years. I hired a very diverse group of people, because you could not hire computer scientists who knew about design or education at that time. My group included one third psychologists and other social scientists; one third programmers; and one third artists and designers. The latter group included an architect, a book designer, a documentary film maker, and a television producer. Together, we created new tools and methods for designing interactive video that let people explore the technology. We eventually turned the video-based tools into a separate product—in the 1980's, a few months before the Macintosh. Did it have the same impact? Clearly no. It was far too expensive.

This all happened at the time of the first CHI conference in 1983, which was in Boston. I discovered a large number of like-minded people who have a nice mix of technical expertise, combined with an interest in human beings and in design. This is what I love about Human-Computer Interaction as a field, which brings us all together, and I have been actively involved in $\mathrm{CHI}$ ever since.

Marcelo. How did you come to work with music, or more generally the arts, and HCI?

Wendy. I have always been interested in the arts, having spent many years playing the violin, singing and dancing. But it did not become a research topic 
until I worked with Catherine Letondal at the Institut Pasteur studying laboratory notebooks. She wanted very much to go to IRCAM, the center for contemporary music in Paris. I hired her as a Postdoc and we worked together on interviews and participatory design with composers there. Next, Fanis (Theophanis) Tsandilas, now a permanent faculty member in my group, and my Ph.D. student, Jérémie Garcia (now an Assistant professor (Maitre de conference) in Toulouse) joined us in what turned out to be a very fruitful and interesting collaboration. I had worked with prototypes of "interactive paper" for many years at Xerox PARC's (Palo Alto Research Center) research center in England (EuroPARC), which we combined with interactive video and mediated communication. By the time we started working with IRCAM, Anoto technology had arrived. It creates truly interactive paper by printing an almost invisible dot paper on ordinary paper, and then using a pen with a tiny embedded video camera to detect the pen's location on the paper. It is an ordinary pen that leaves ink as you write, but also captures a digital trace of that ink.

We had observed the incredibly creative ways that composers sketched ideas for new compositions on paper and thought this would be a perfect opportunity to explore interactive paper. Rather than simply writing notes on a score, they set creative constraints and work within them as they develop and refine their ideas. They work with extremely powerful music composition software, but it lacks the freedom of expression they enjoy with paper. We explored how to link their creative process on paper to this music software, and, in a few cases, used interactive paper as tool for live performance. Over the years, we have worked with a wide variety of creative professionals, including artists and designers (especially graphic designers and choreographers), as well as scientists who explore data. Artists and scientists are my favorite research participants because they are endlessly creative--they push the limits of technology, discover interesting innovations, but also generate weird problems. They look at things from a different angle and challenge our traditional ways of thinking.

Marcelo. They co-adapt.

Wendy. Yes, they co-adapt, exactly. I have learned a lot by working with them. Sometimes my colleagues question my decision to work with creative professionals, and assume that I am somehow trying to 'make them creative'. But no, these people are already extremely creative (that's why they chose their profession!). I view the design problem as how to support their existing creative processes, perhaps by sparking ideas, documenting their work, or helping them execute something, but the primary goal is to avoid getting in their way!

Marcelo. This leads to the next question: What is your perspective on usercentered design or participatory design in music technology? 
Wendy. I would say that almost everything we do is participatory design. Of course, you have to first think about who the participants are. For example, Olivier Bau, Atau Tanaka, and I worked on the $A 20$ music player (Bau et al., 2008) a 20 -sided set of speakers that plays different music according to how you turn and interact with it. We ran participatory design workshops with college students who play music but were not professional musicians. Other cases, such as Musink (Tsandilas et al. 2009) were specifically designed for professional composers. Fanis Tsandilas and I also worked on Knotty Gestures (Tsandilas and Mackay, 2010), which was designed for people with an existing composition practice to create their own composition languages. Both use interactive paper-composers design their own notations and embed corresponding computation into their sketches and drawings.

A more recent variation, called Knotation (Ciolfi Felice et al. 2018) with Marianela Ciolfi Felice and Sarah Alaoui, is the result of extensive participatory design workshops with choreographers and dancers. They use an iPad to draw interactive floor plans and timelines, and embed video clips and other interactive features. We saw an interesting contrast between the composers' and the choreographers' creative practices. Composers can work alone, but choreographers usually work with dancers. They may create the design in their heads, but they work out the details through the dancers' bodies. Although we observed one composer who composed for a specific muse, a particular woman who played a particular cello, most composers worked with sounds to create music and the choreographers worked with dancers' bodies to create dance.

Marcelo. And are there any limitations in participatory design?

Wendy. Sure. One thing that is critical, but also, I have to admit, a limitation, is that we design for specifics. We work with a specific artist who has a specific practice, as they explore a specific idea in the context of a specific piece. Although this always reveals generalities, we focus our designs on the specifics. What makes this process work is that we learn from multiple artists as they create different projects and seek generalities across them. For example, we discovered that all composers and choreographers create a set of personal constraints for each piece. The specific constraints differ, but the idea of creating your own constraints and working within them was general to everyone. So systems such as MusicInk, Knotty Gestures and Knotation each provide a simple way for the artist to express and interact with their own constraints. Participatory design gave us a deep understanding of specific creative practices. The generalities that emerged can support a wide variety of new creative practices.

Marcelo. How important is the evaluation of new technology, especially instruments and interfaces?

Wendy. I am not really a fan of "Let's evaluate how creative this was or how good this piece was" because I do not think... 
Marcelo. "Ten graduate students from our lab took part in the experiment..."

Wendy. Yes, exactly. This only works if the goal is to increase performance, not to provide creative tools for creative professionals. You end up pretending to do something that is not real. That said, I do think that we can learn from what we have done. We just learn different things--not only what the technology does and how well it does it, but also how well it supports things we did not expect. There is what Wanda Orlikowski calls 'interpretive flexibility' or people's ability to appropriate the technology. Formal experiments tend to focus on whether or not it does the thing we said it was going to do ...

Marcelo. How well did it work...

Wendy. Yes. You can measure that, but I think it is more interesting to explore how far afield people were able to go. How much did they explore and do new things that neither you nor they expected? That is also a valuable contribution and a legitimate thing to evaluate. Researchers evaluate both the technology and the human side, usually in terms of their preferences. I prefer to focus on the details of the interaction in a particular context, according to three principles:

- Is it discoverable?

- Is it appropriable?

- Is it expressive?

For example, you can ask "What does it take for the user to discover how it works and what it can do?" This is a more "user-friendly' version of the idea of co-adaptation. We ask how people can adapt to the technology-can they learn how to make it do what it was designed to do? --and whether they can adapt the technology — can they appropriate it and adapt it to accomplish other things? We are also interested in a third aspect, especially for creative professionals but also for everyone else, that is, is the technology expressive? Can the system capture human variation, both intentional and unintentional? Can users control it, but also be surprised by and work with it? This is essential for any kind of artistic endeavor, whether music or dance or design or any other creative practice.

Marcelo. So, you would define expressiveness as variations and ways to control something in subtle ways...

Wendy. Yes. Are we designing technology or are we designing interactive experiences? We can assess technology according to how expressive it is, right? Not on an absolute scale, such as seven on a scale of one to ten, but from the user's perspective-Does the technology react differently according to who used it? For example, if I write a text message on my phone and you write the same message, nobody would be able to distinguish them - it's all just text, in the same font and size. But if we each handwrite that message, our handwriting 
differentiates us. We can not only tell who wrote which message, but whether or not we were in a hurry or writing on moving bus. Sally (Jessalyn) Alvina and Joe Malloch designed the Expressive Keyboard (Alvina et al. 2016) which uses 'gesture typing' to draw words on a soft keyboard. We can map features of each gesture to different colors or expressions on emojis and are now working with a professional typographer who has created a set of beautiful fonts that vary based on how you draw each word. You can write normally or, if you exaggerate in different ways, you can produce an elegant script, colorful, fanciful fonts for children, etc. The user benefits from word recognition, while generating a personal expressive output.

Marcelo. The issue is that a lot of people talk about instruments that are expressive, but actually instruments are not expressive--it is people's interactions with them that are perceived as expressive.

Wendy. Exactly. That is why I began by talking about the technology but shifted the focus to people-for me, expressivity appears on the human side. As for evaluation, I think you have to be careful about which questions you ask. Just because HCI researchers know how to do hypothesis-testing style experiments, does not mean we should always use them. I like to use what I call 'structured observation'. Instead of starting with a full, operationalized hypothesis, we interview and observe users and identify the areas where we think something interesting is likely to occur. We then ask people to perform various activities in a particular setting, such as modifying a music composition or creating a new twominute dance piece, and carefully observe what happens. We look for interesting phenomena that can inspire ideas. This is an intermediate stage of exploration, with the goal of increasing our chances of detecting something new and studying it further.

This kind of exploration increases the likelihood of discovering phenomena that are worth studying, rather than skimming the surface and designing for stereotypes. We educate ourselves first by observing, interviewing, participating. We then perform structured observations in the most promising areas and force ourselves to pay attention to surprises. This helps us ask deeper research questions and design more innovative technology. Frankly, I think good researchers do this all the time, they just do not talk about it.

Marcelo. This is interesting. Perhaps it could be one solution for the evaluation issue.

Wendy. Yes. I think problem finding is harder than problem solving. If you find a good problem, solving it is usually pretty straightforward. The trick is how to articulate an interesting new design problem. 


\section{References}

1. J. Alvina, J. Malloch, and W.E. Mackay (2016). Expressive Keyboards: Enriching GestureTyping on Mobile Devices. In Proceedings of the ACM Symposium on User Interface Software and Technology (UIST 2016), Tokyo, Japan. pp. 583-593.

2. O. Bau, A. Tanaka and W.E. Mackay (2008). The A20: Musical Metaphors for Interface Design. In Proceedings of the ACM International Conference on New Interfaces for Musical Expression (NIME 2008), pp. 361-366.

3. T. Tsandilas, C. Letondal and W.E. Mackay (2009) Musink: Composing Music through Augmented Drawing. In Proceedings of the ACM SIGCHI conference on Human factors in computing systems (CHI 2009), Boston, MA, pp.819-828.

4. T. Tsandilas and W.E. Mackay (2010) Knotty Gestures: Subtle Traces to Support Interactive Use of Paper. In Proceedings of ACM Advanced Visual Interfaces (AVI 2010), Rome, Italy, pp. 147-154.

5. M. Ciolfi Felice, S. Fidili Alaoui, and W.E. Mackay (2018) Knotation: Exploring and Documenting Choreographic Processes. In Proceedings of the ACM SIGCHI conference on Human factors in computing systems (CHI 2018), Montréal, Canada, 12 pages. 